Article

\title{
Intensified Pozzolanic Reaction on Kaolinite Clay-Based Mortar
}

\author{
Yang-Hee Kwon ${ }^{1}$, Sung-Hoon Kang ${ }^{1,2}$, Sung-Gul Hong ${ }^{1, *}$ and Juhyuk Moon ${ }^{2, *}$ \\ 1 Department of Architecture \& Architectural Engineering, Seoul National University, 1 Gwanak-ro, \\ Gwanak-gu, Seoul 08826, Korea; yanga1126@naver.com (Y.-H.K.); medesis@naver.com (S.-H.K.) \\ 2 Department of Civil and Environmental Engineering, National University of Singapore, \\ 1 Engineering Drive 2, Singapore 117576, Singapore \\ * Correspondence: sglhong@snu.ac.kr (S.-G.H.); ceemjh@nus.edu.sg (J.M.); \\ Tel.: +82-2-880-8360 (S.-G.H.); +65-6516-4574 (J.M.)
}

Academic Editor: Jorge de Brito

Received: 20 February 2017; Accepted: 16 May 2017; Published: 18 May 2017

\begin{abstract}
The objective of this study is to develop and characterize kaolinite clay-based structural mortar. The pozzolanic reaction induced from two mineral additives, i.e., calcium hydroxide and silica fume (SF), and the physical filling effect from SF, were found to be effective on the enhancement of structural properties. Based on several preliminary experiments, 7:3 ratio of kaolinite clay/calcium hydroxide was selected as a basic binder. Then, the amount of SF was chosen as $0 \%, 7.5 \%$, and $15 \%$ of the total binder to consider both the chemical and physical effects. The results showed that compressive strengths of samples with $7.5 \%$ and $15 \% \mathrm{SF}$ are significantly increased by approximately $200 \%$ and $350 \%$, respectively, at 28 days compared to the sample without SF. However, based on the results of the sample with $15 \% \mathrm{SF}$, it is found that excessive addition of SF causes long-term strength loss, possibly owing to micro cracks. With the careful consideration on this long-term behavior, this suggested new mix design can be further extended to develop sustainable structural materials using natural minerals or waste materials with nonbinding properties.
\end{abstract}

Keywords: cementless mortar; silica fume; kaolinite clay; pozzolanic reaction; compressive strength; microstructure

\section{Introduction}

Concrete is one of the most widely used construction materials in the world with a consumption of almost 10 billion tons per year [1]. It has numerous advantages as a structural material, such as convenience for making the shape of a structure, structural soundness, and good durability. Recently, however, the ordinary Portland cement (OPC) has been regarded as environmentally harmful because its manufacturing process generates a significant amount of carbon dioxide $\left(\mathrm{CO}_{2}\right)[2] \cdot \mathrm{CO}_{2}$ is considered as one of greenhouse gases that is associated with global warming and climate change [3]. In addition, OPC production gives rise to other environmental concerns, such as large amounts of dust during handling and high energy consumption to attain high kiln temperatures [4].

As a result of extensive research activities focusing on the development of eco-friendly construction materials, several promising alternatives have been proposed for low $\mathrm{CO}_{2}$-embedded construction materials. These include high-volume fly ash [5,6] or slag [7] concrete, geopolymer concrete [8], and sustainable cement mixtures having $\mathrm{CO}_{2}$-sequestrated minerals [9], or fillers such as limestone or quartz powder [10-13]. In addition, materials having pozzolanic properties, such as fly ash (type F), slag, and SF are receiving attention as sustainable supplementary cementitious materials [14-18]. Along with the environmental and economic benefits as replacements for OPC, these materials also have other advantages, such as improving mechanical properties and durability [19]. 
In addition to these industrial byproduct-based pozzolanic materials, there are natural pozzolans, such as volcanic ash [20], diatomaceous earth [21], and kaolinite mineral [22].

As a sustainable building material, kaolinite clay (also known as hwangtoh clay in Korea) has been used for more than 1500 years in traditional houses in Korea, where there are enough reserves [23]. It consists primarily of kaolinite and quartz. Owing to its abundance and sustainable benefit, it has been studied by Korean researchers as a potential supplementary or main building material [23,24]. The well-known advantages as a building material include high heat-storing capacity and its purifying, deodorizing, and antibiotic properties [25]. Moreover, when heating through Ondol (traditional floor heating system in Korea), the infrared radiation emission from the clay was confirmed to be beneficial to the human body [25]. With these advantages, it has been used as plastering, flooring, and finishing materials for buildings up to the present time $[23,26]$. From a mix design perspective, the clay has been customarily mixed with sand and lime [27], as stated in Korean building standards [28]. However, the clay (the kaolinite mineral is the main reactive component in the clay) simply mixed with lime does not provide sufficient strength for construction applications. The main reason for the low compressive strength ( $<3 \mathrm{MPa}$ ) of kaolinite clay-based mortar (water-to-binder ratio of 0.5 to 0.6 ) is reported as the poor pozzolanic reaction between the kaolinite clay and lime [29]. This limits the application of this sustainable building material to mostly non-structural elements.

To improve the mechanical strength of kaolinite clay, several studies were performed. The most well-known method to increase its reactivity is the heating of the clay up to $600^{\circ} \mathrm{C}$ and above $[4,26]$. OPC mixed with the heated kaolinite clay is also suggested $[25,30]$. However, the heated clay with or without the OPC has a shortcoming of high energy consumption. The application of the geopolymer reaction using alkali activators is another interesting approach [23]. However, this also has disadvantages, such as significant workability loss because of rapid reaction, the hazard of handling an alkali solution, and high cost [31,32]. In order to overcome these shortcomings, it is necessary to develop a new mixing formula for kaolinite clay-based mortar with improved material properties.

In this study, a new mix proportion of the kaolinite clay-based mortar was developed. To increase its reactivity, an intensified pozzolanic reaction was intended by adding SF and hydrated lime together on the kaolinite clay. SF, known as microsilica, is a highly effective pozzolanic material due to its high silica content and extreme fineness [33,34]. The addition of SF is expected to play a key role on the enhancement of material properties by providing the physical filling effect and the pozzolanic reaction with added hydrated lime. In this study, a series of experiments of compressive strength, heat of hydration, dimensional stability, and microstructural analysis was performed to evaluate the effects of the mineral admixtures on various material properties of kaolinite-based clay mortar.

\section{Experimental}

\subsection{Materials}

The scanning electron microscope (SEM, JSM-7800F Prime from JEOL Ltd., Tokyo, Japan) images of all used materials are shown in Figure 1. The chemical compositions determined by $\mathrm{X}$-ray fluorescence (XRF-1700, Shimadzu, Tokyo, Japan) are summarized in Table 1. Kaolinite clay was obtained from Gochang-goon, Chonnam, Korea. As shown in Table 1, the main oxide components of the clay are $\mathrm{SiO}_{2}$ $(55.34 \%), \mathrm{Al}_{2} \mathrm{O}_{3}(22.33 \%)$, and $\mathrm{Fe}_{2} \mathrm{O}_{3}(8.43 \%)$, while the hydrated lime is mainly composed of $\mathrm{CaO}(74.51 \%)$.

Table 1. Oxide compositions of used materials (wt \%).

\begin{tabular}{ccccccccccccc}
\hline $\begin{array}{c}\text { Chemical } \\
\text { Composition }\end{array}$ & $\mathrm{SiO}_{2}$ & $\mathrm{Al}_{2} \mathbf{O}_{3}$ & $\mathrm{TiO}_{2}$ & $\mathrm{Fe}_{2} \mathbf{O}_{3}$ & $\mathbf{M g O}$ & $\mathrm{CaO}$ & $\mathbf{N a}_{2} \mathbf{O}$ & $\mathbf{K}_{\mathbf{2}} \mathbf{O}$ & $\mathbf{M n O}$ & $\mathbf{P}_{\mathbf{2}} \mathbf{O}_{\mathbf{5}}$ & LOI $^{\mathbf{1}}$ & Total \\
\hline Kaolinite clay & 55.34 & 22.33 & 1.04 & 8.43 & 0.52 & 1.46 & 0.10 & 2.49 & 0.07 & 0.10 & 8.02 & 99.91 \\
Hydrated lime & 0.57 & 0.54 & 0.01 & 0.14 & 1.12 & 74.51 & 0.01 & 0.12 & 0.004 & 0.01 & 23.00 & 100.03 \\
Silica fume & 96.90 & 0.29 & 0.01 & 0.15 & 0.18 & 1.54 & 0.16 & 0.64 & 0.03 & 0.05 & 0.02 & 99.97 \\
\hline \multicolumn{18}{c}{ Loss on ignition. }
\end{tabular}


The particle size distributions of kaolinite clay, hydrated lime, and SF are presented in Figure 2, which were determined by laser diffraction method using Mastersizer 3000 (Malvern Instruments, Malvern, UK). Used $\mathrm{SF}\left(\mathrm{SiO}_{2}>96.9 \%\right)$ has a density of $2.2 \mathrm{~g} / \mathrm{cm}^{3}$ and specific surface area of $200,000 \mathrm{~cm}^{2} / \mathrm{g}$. In this study, the particle size distribution of SF was measured again using image-processing technique to correct its agglomeration effect during the laser diffraction measurement [35]. To obtain more accurate particle size distribution of SF, 20 SEM images containing total 3720 SF particles were analyzed under various magnifications $(30,000 \times-100,000 \times)$. The obtained new distribution curve of SF is added in Figure 2. The laser diffraction method could not detect the particles smaller than $100 \mathrm{~nm}$ (except for very fine particles of $5-11 \mathrm{~nm}$ ) due to its agglomeration effect. Thus, the highest volume density is formed at $265 \mathrm{~nm}$ (Figure 2a); while image-processing method detected the particles between $40-100 \mathrm{~nm}$ and yielded the highest density peak at $172 \mathrm{~nm}$. This comparison reveals that a significant portion of small SF particles cannot be detected and the particle size can be overestimated from the laser diffraction method.

The fine aggregate satisfies the international organization for standardization (ISO) standards [36] which regulates that $\mathrm{SiO}_{2}$ contents are no less than $98 \%$ and the particle size is ranged between $80 \mu \mathrm{m}$ and $2 \mathrm{~mm}$.
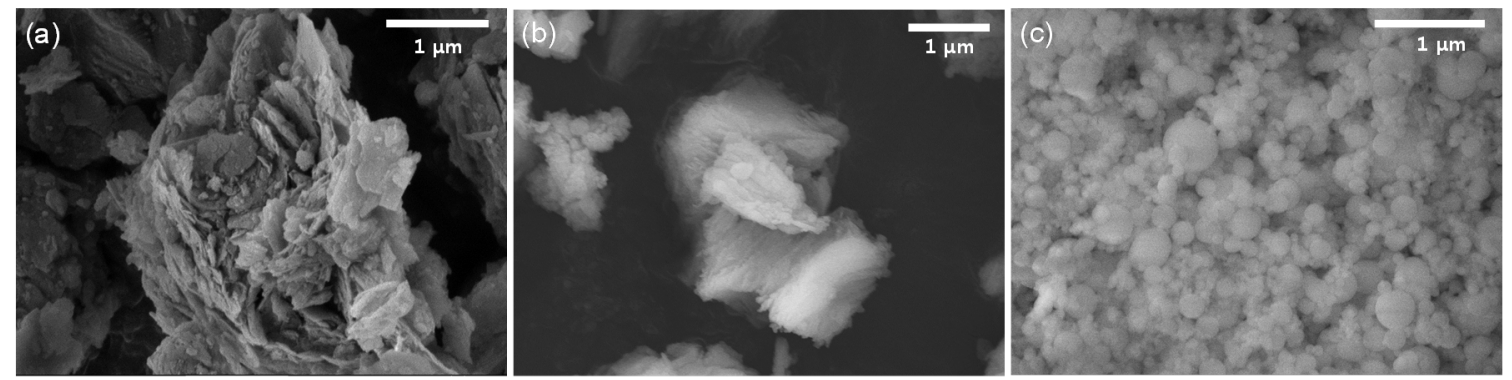

Figure 1. Scanning electron microscope (SEM) image of used materials: kaolinite clay (a), hydrated lime (b), and SF (c).
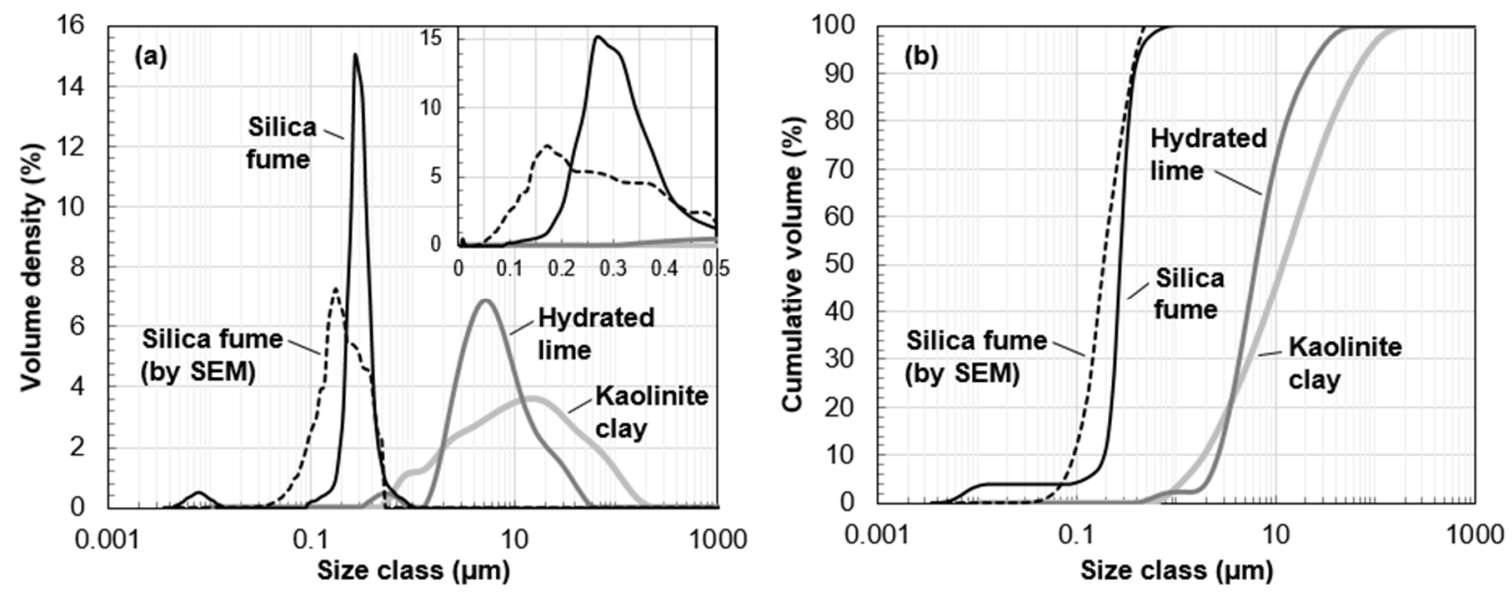

Figure 2. Particle size distributions of raw materials used in kaolinite clay based mortar: (a) volume density, and (b) cumulative volume. Line curves from laser diffraction method and dot-curve from image-processing method.

\subsection{Mix Proportion}

Mix proportions of the kaolinite clay-based mortar are shown in Table 2. Both kaolinite clay and hydrated lime are considered as binder materials. The main variable is SF to binder ratio, which was set as $0 \%, 7.5 \%$, and $15 \%$ by weight of the binder. The reference sample (Ref) does not include SF, 
while SF_7.5 and SF_15 samples contain 7.5\% and 15\% of SF, respectively. The water to binder ratio (W/B) for all samples was maintained at $40 \%$. Polycarboxylate-ether type superplasticizer was added to the mixing water to obtain workability. The ratio of fine aggregate to binder was determined as 3 by several preliminary tests.

Table 2. Mix proportions of kaolinite clay based mortar (by weight ratio of binder).

\begin{tabular}{|c|c|c|c|c|c|}
\hline \multirow{2}{*}{$\begin{array}{l}\text { Sample } \\
\text { Name }\end{array}$} & \multirow{2}{*}{ Water/Binder } & Total Binder (\%) & \multirow{2}{*}{ SF/Binder } & \multirow{2}{*}{ Superplasticizer/Binder } & \multirow{2}{*}{$\begin{array}{c}\text { Fine } \\
\text { Aggregate/Binder }\end{array}$} \\
\hline & & Kaolinite Clay/Hydrated Lime & & & \\
\hline Ref & & & 0 & & \\
\hline SF_7.5 & 0.4 & $70: 30$ & 0.075 & 0.06 & 3 \\
\hline SF_15 & & & 0.15 & & \\
\hline
\end{tabular}

\subsection{Specimen Preparation}

The mortar was mixed according to ASTM C305 [37] using a five-liter Hobart mixer. Dry kaolinite clay, hydrated lime, and fine aggregate were blended for $30 \mathrm{~s}$. When preparing SF_7.5 and SF_15 samples, SF was mixed with the dry materials together. Then, water and superplasticizer were added to the dry mixture and mixed for $3 \mathrm{~min}$ at low speed $(140 \pm 5 \mathrm{rpm})$ and another $1 \mathrm{~min}$ at high speed $(285 \pm 10 \mathrm{rpm})$. After mixing, the mortar was placed and compacted in the prepared molds. All specimens were wrapped with vinyl sheets to prevent moisture loss and were cured in a steam chamber $\left(60 \pm 2{ }^{\circ} \mathrm{C}\right.$, RH $\left.95 \pm 5 \%\right)$ for $72 \mathrm{~h}$. This curing condition was chosen considering the typical precast concrete production. After demolding at $72 \mathrm{~h}$, all samples were cured in a constant temperature and humidity chamber $\left(20 \pm 2{ }^{\circ} \mathrm{C}, \mathrm{RH} 60 \pm 5 \%\right)$ until the test.

\subsection{Test Method}

The heat of hydration was measured for $72 \mathrm{~h}$ at $60^{\circ} \mathrm{C}$ using an isothermal calorimeter (TAM AIR, TA Instruments, New Castle, DE, USA). For each measurement, $15 \mathrm{~g}$ of fresh paste without fine aggregate was prepared by assuming that the aggregate is inert. The total heat of hydration was determined by integrating the heat flow curve. To compare the hydration reaction quantitatively, the measured hydration heat was normalized by weight of the binder in each paste.

$\mathrm{X}$-ray diffraction (XRD) analysis was performed to investigate the mineralogical characteristics of all raw materials and hydrated samples (without fine aggregate). After 28 days of curing, the crushed and grounded pastes were placed in a holder to perform the analysis. Each sample was scanned from $5^{\circ}$ to $80^{\circ}(2 \theta)$ with a step size of $0.0033^{\circ}$ using Miniflex (Rigaku, Tokyo, Japan). The crystalline phases were identified by comparing Bragg peak positions and intensities from the inorganic crystal structure database (ICSD) [38].

The compressive strength was measured according to ASTM C 109/C 109M [39]. Cubic specimens $(50 \mathrm{~mm} \times 50 \mathrm{~mm} \times 50 \mathrm{~mm})$ were tested at $1,3,7,14,28,56$, and 91 days using a hydraulic universal testing machine (UTM). The strength was determined as an average of three replicates.

To investigate the porosity and pore size distribution, mercury intrusion porosimetry was used. Three hydration stages of 14,28 , and 91 days were selected, and mercury parameters were set to values of $485 \mathrm{erg} / \mathrm{cm}^{2}$ for the surface tension and $130^{\circ}$ for the contact angle.

\section{Results and Discussion}

\subsection{Heat of Hydration}

The heat flow evolution of kaolinite clay-based mortar is shown in Figure 3a. All samples have two main peaks regardless of SF addition. Abrupt increases of heat flow within $2 \mathrm{~h}$ were measured for all samples almost identically. This infers that experiments were reliably conducted, and the addition of SF does not alter the start of first hydration reaction. The second main peak initiated at $12 \mathrm{~h}$ and reached its maximum at $20 \mathrm{~h}$ in the Ref sample, whereas it starts quickly from $5 \mathrm{~h}$ in samples with SF. 
This observation supports the acceleration of the start of the main hydration reaction and increases in the duration of its period due to the addition of SF. As a result, the main hydration reaction was significantly intensified. This eventually results in a larger amount of cumulative heat of hydration as shown in Figure 3b. As will be explained later, this intensified hydration reaction is the intended pozzolanic reaction between amorphous silica and hydrated lime.
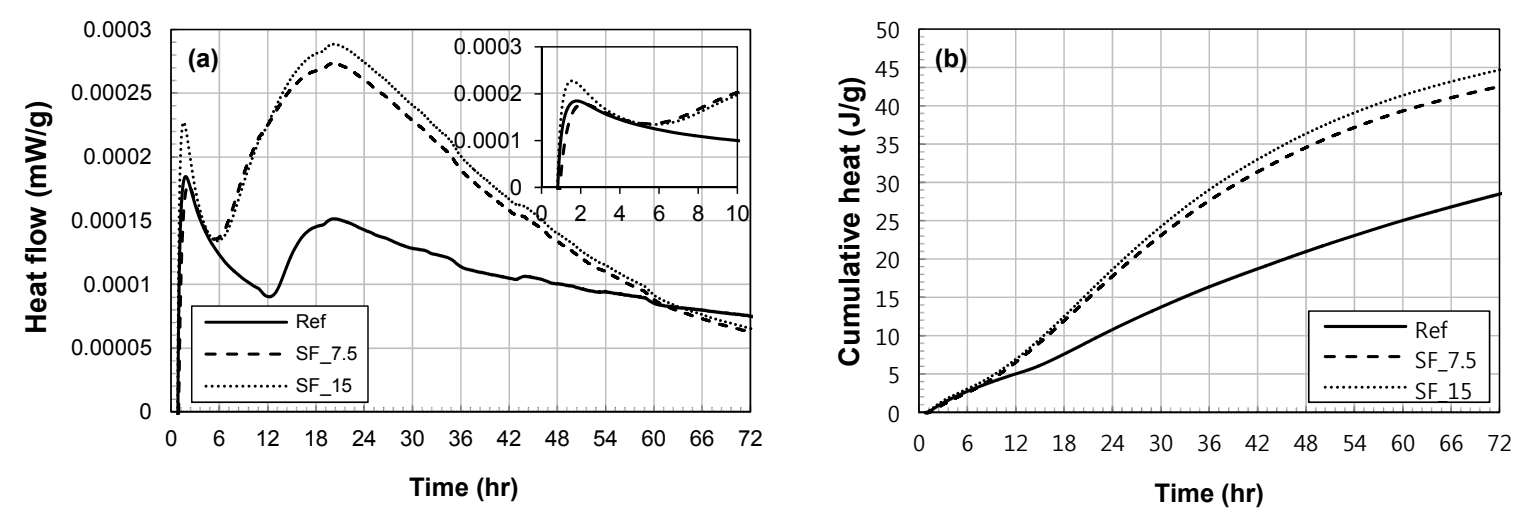

Figure 3. Heat of hydration of kaolinite clay based mortars with SF contents: hydration heat flow evolution (a), and cumulative heat of hydration (b).

Although the samples with SF emitted more cumulative heats compared to Ref (Figure 3b), there is no noticeable difference in the heats between two samples with SF (the heats are $42.53 \mathrm{~J} / \mathrm{g}$ and $44.67 \mathrm{~J} / \mathrm{g}$ in SF_7.5 and SF_15, respectively). Thus, it can be concluded that an excessive addition of SF (e.g., more than $7.5 \mathrm{wt} \%$ of SF) scarcely contributes to the enhancement of hydration reaction during heat treatment period. However, it may improve the strength because of the physical filling effect by unreacted SF particles, which will be discussed later.

\subsection{XRD Analysis}

The results of XRD analysis of raw materials and hydrated kaolinite clay-based pastes at 28 days are shown in Figure 4. The kaolinite clay is composed of quartz, kaolinite, and illite. Hydrated lime consists of mostly calcium hydroxide and calcium carbonate. SF contains only amorphous silica. In all hydrated samples, an alumino-silicate type of mineral (clinoptilolite) is found. However, while calcium hydroxide is strongly detected in Ref (see red-dotted boxes in Figure 4), it is almost not detected in samples with SF (SF_7.5 and SF_15). It is obvious that calcium hydroxide was consumed by the pozzolanic reaction induced from the addition of SF [40,41].

Quartz from kaolinite clay is detected in all hydrated samples. The intensity of quartz peak (at $26.5^{\circ}$ theta) increases with addition of SF (see blue-dotted box in Figure 4). This can be explained by calcium hydroxide in hydrated lime preferentially reacting with amorphous silica first rather than with quartz. Thus, the intensity of unreacted quartz peak is the highest in SF_15. This observation also shows that crystalline quartz in kaolinite clay can react with calcium hydroxide to some extent as a pozzolanic agent. The kaolinite peak (at $12.2^{\circ}$ theta) is slightly weaker in samples with SF. Along with the fact that kaolinite has a weak pozzolanic reactivity [42], the weakness of peak intensity can be also due to the smaller absolute amount of the clay in the paste by the SF addition (Table 2).

Meanwhile, the calcium carbonate peak (at $29.4^{\circ}$ theta) of the hydrated sample increases with SF addition (see purple-dotted box in Figure 4). As can be confirmed by the XRD result, calcium carbonate was initially included in raw hydrated lime. However, the same amount of hydrated lime was added in all samples during the mixing process. In this sense, it is interesting to note that the intensity of calcium carbonate is higher in SF_7.5 or SF_15 than that in Ref. In our system, SF addition increased the carbonation reaction in kaolinite clay-based mortar that contains calcium hydroxide. Similarly, 
it has been previously reported that the addition of SF increases the carbonation depth of cementitious materials [43,44].

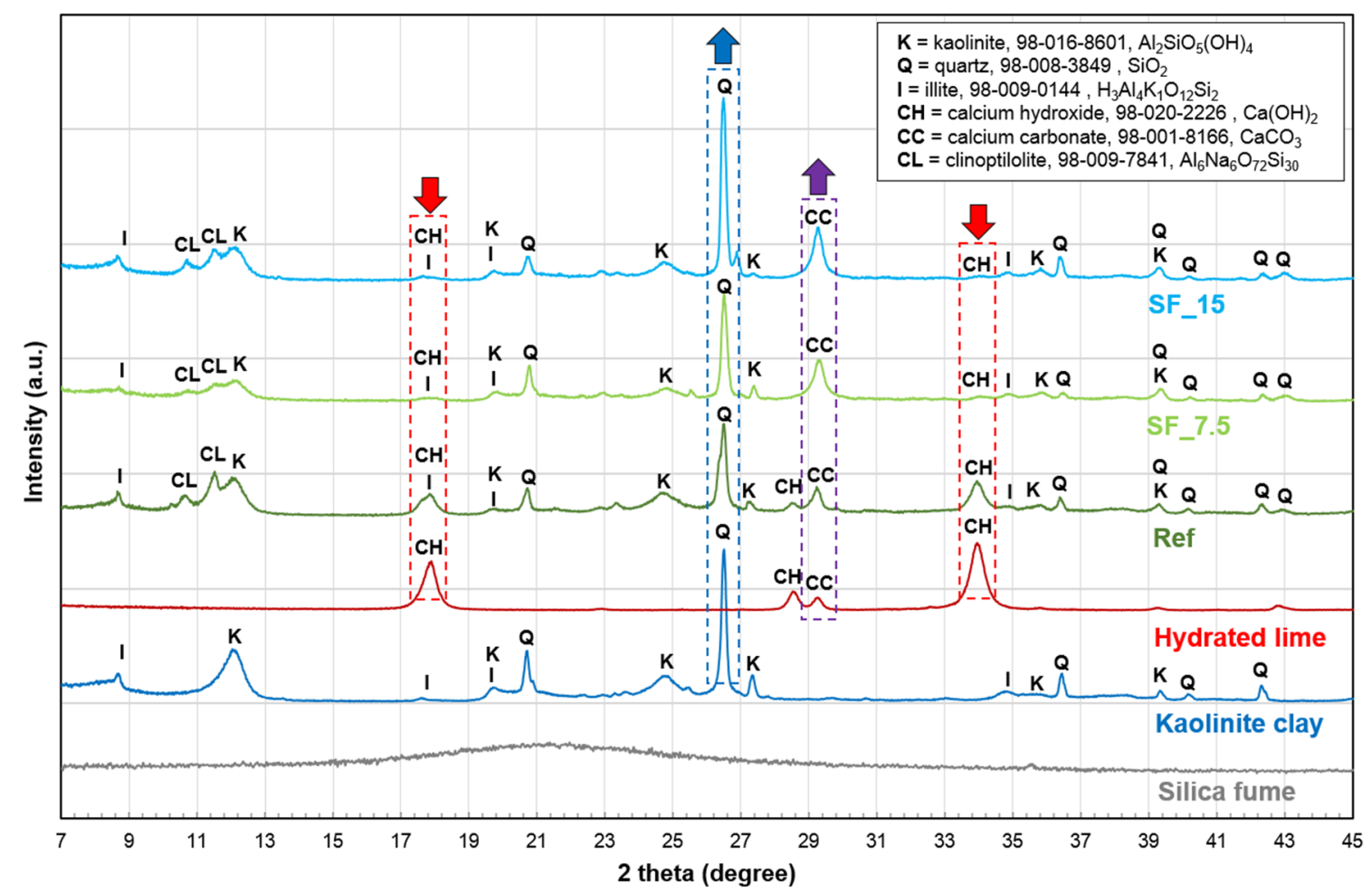

Figure 4. X-ray diffraction spectra with qualitative analysis of kaolinite clay based mortars.

\subsection{Porosity Analysis}

The results of pore structure analysis are shown in Figure 5. The cumulative pore volume of all samples decreases with curing ages (Figure $5 d-f$ ). Figure $5 a-c$ compare pore size distributions of the samples with different curing days. It is observed that there are differences in the first peaks of pore diameters depending on SF contents. The first peaks of both Ref and SF_7.5 are formed nearly at $100 \mathrm{~nm}$ and are not changed with the number of curing days (Figure $5 \mathrm{a}, \mathrm{b}$ ). On the other hand, the peak of SF_15 is formed at $9 \mathrm{~nm}$, which is approximately $1 / 10$ times compared to the others (Figure 5c). This difference is owing to the physical filling effect by the surplus SF, and it contributed to fine pore structure of SF_15, which will be discussed in detail.
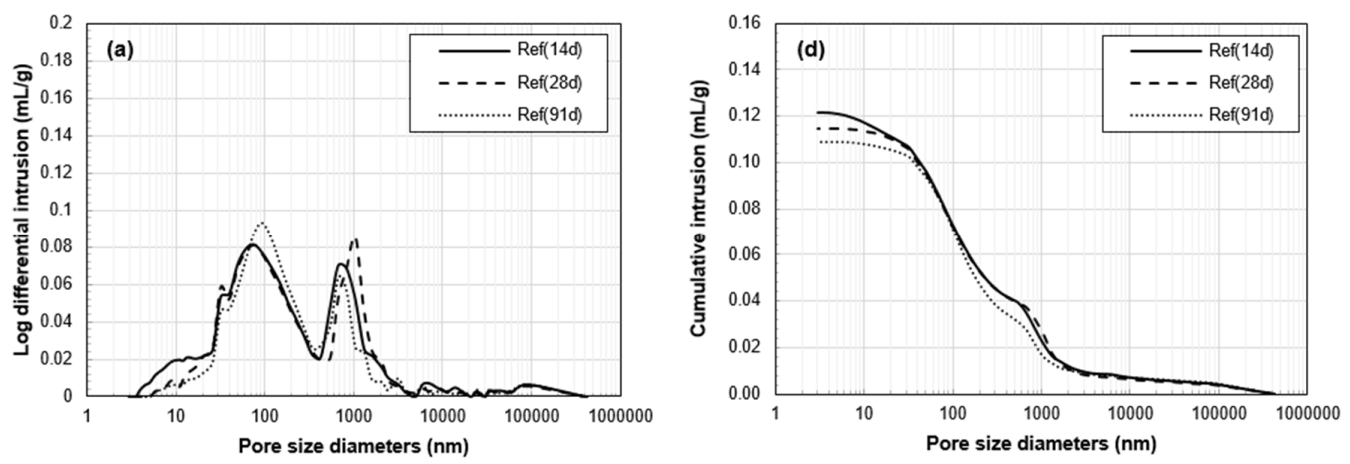

Figure 5. Cont. 

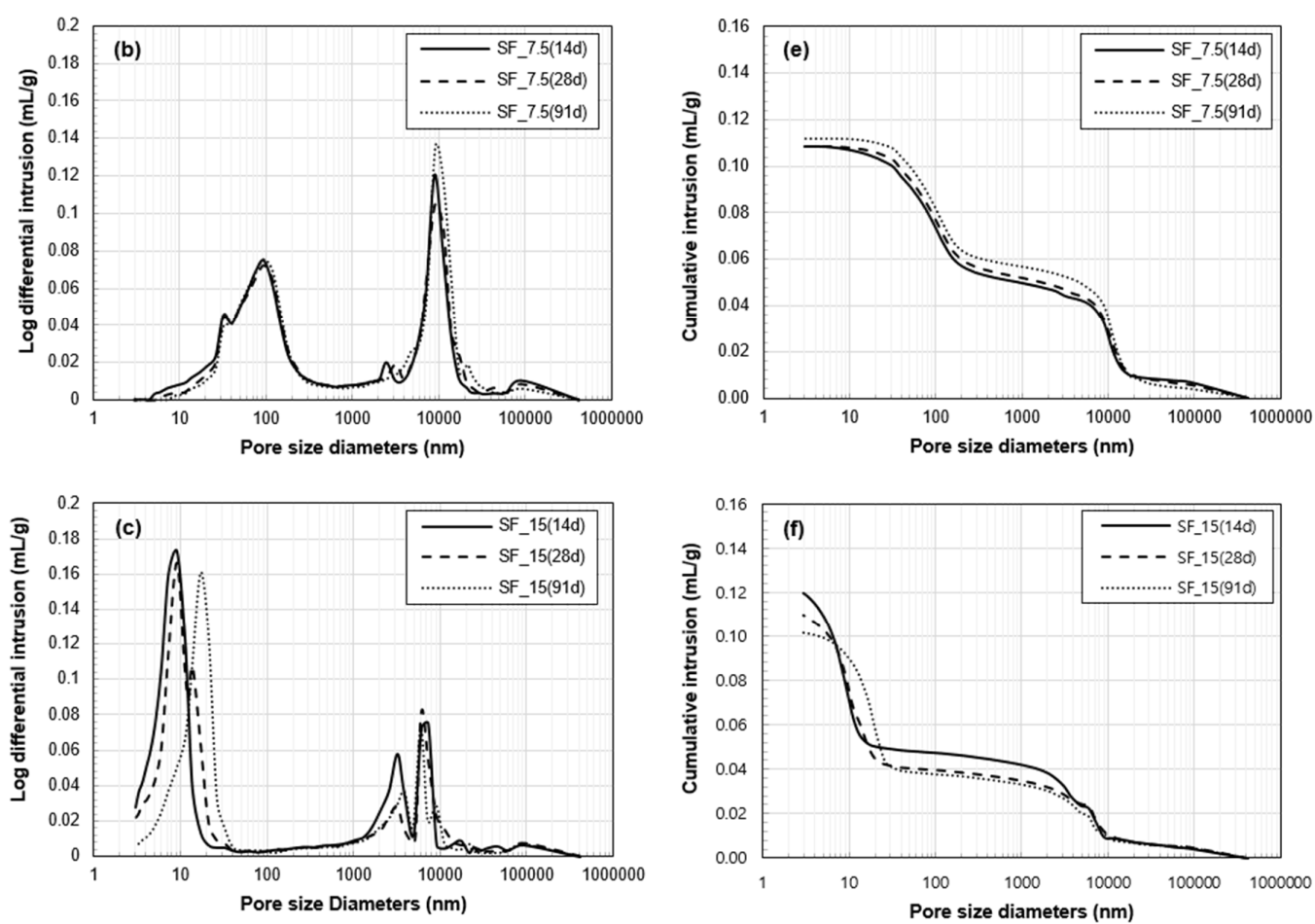

Figure 5. Porosimetry of kaolinite clay based mortar: log differential intrusions of Ref (a), SF_7.5 (b), and SF_15 (c), and cumulative pore volume of Ref (d), SF_7.5 (e), and SF_15 (f).

As can be seen in Figure 6 that compares cumulative pore volumes of three samples at 28 days, the extra SF (over $7.5 \mathrm{wt} \%$ ) is expected to play a role as a filler. Pores of the mortar between 40 and $500 \mathrm{~nm}$ in their diameter can be filled with the extra (unreacted) SF, because its size distribution (see Figure 2) coincides with the pore range. Thus, a part of macropores $(25 \mathrm{~nm}-5 \mu \mathrm{m})$ [45] could be effectively filled with the filler, while increasing the volume of the smaller pores $(<25 \mathrm{~nm})$. In short, this filling effect led SF_15 to have fine pore structure (Figure 6b).
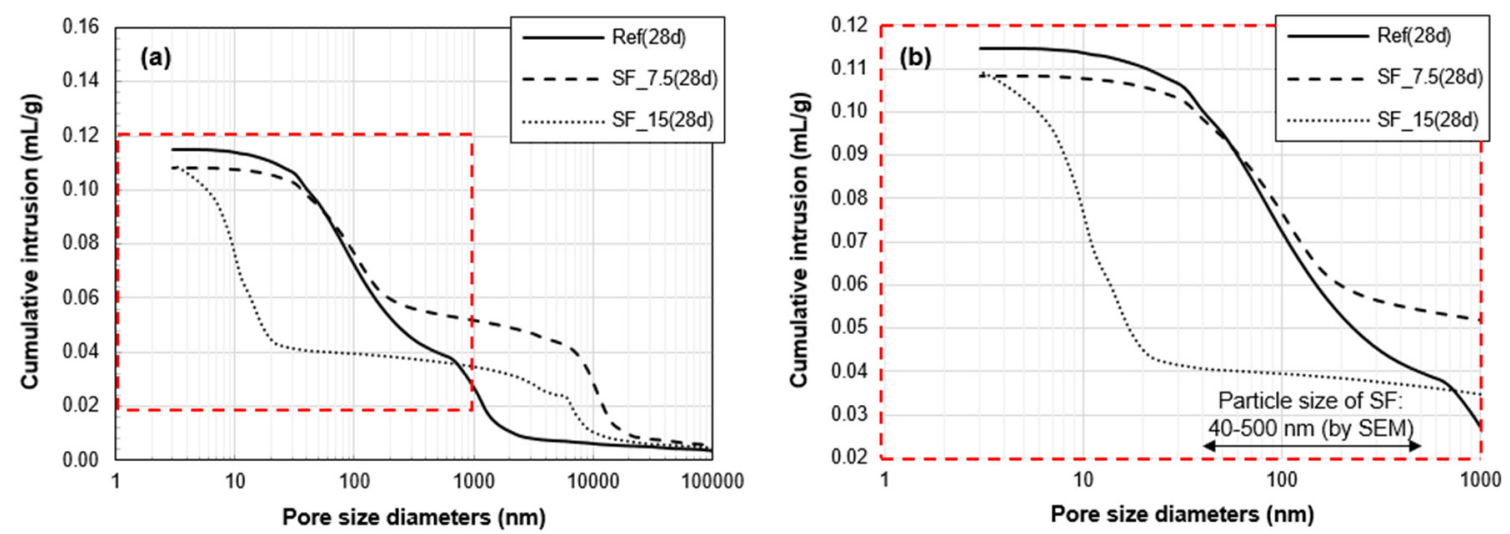

Figure 6. Cumulative pore volume (a), and classification of pozzolanic and filling effects (b) at 28 days.

The second peak position of the two samples with SF (SF_7.5 and SF_15) are formed at approximately $10 \mu \mathrm{m}$, which is 10 times larger than that in Ref (Figure $5 \mathrm{a}-\mathrm{c}$ ). The pore range of this peak $(5-50 \mu \mathrm{m})$ is related to preexisting microcracks and entrained or entrapped air [45]. These pores, which did not change with curing ages, were possibly formed with the change of rheology of the mortar by SF addition [46]. 
The measured pore volume was divided into four size ranges in Figure 7, on the basis of the international union of pure and applied chemistry system [45]. However, the micropore range was modified from $<1.25 \mathrm{~nm}$ to $<4.5 \mathrm{~nm}$ based on the previous studies which have shown that the enhanced pozzolanic reaction considerably changes the pore structure especially below $4.5 \mathrm{~nm}$ range [15,47]. Thus, this modification can help to effectively explain the change of pore structure by the intensified pozzolanic reaction.

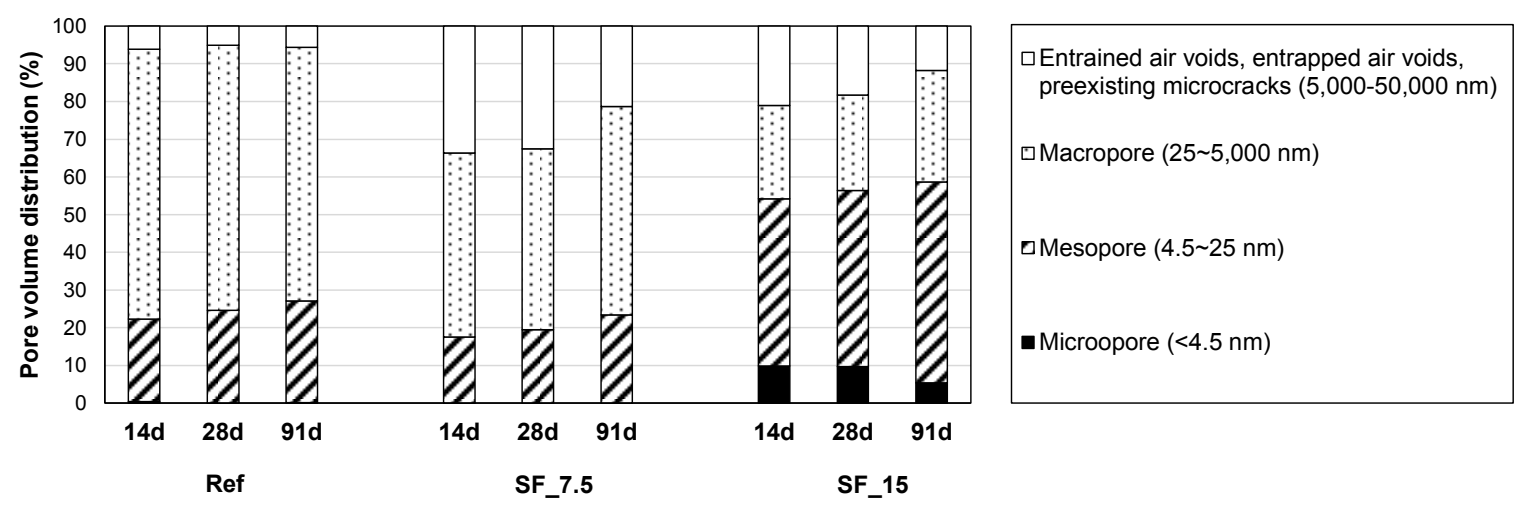

Figure 7. Pore volume distributions at different curing days.

As expected by Figure 5, the proportions of micro and mesopores of SF_15 are significantly higher than those of the other samples, due to the physical filling effect. However, the proportion of micropores of SF_15 steadily decreased with curing age. In particular, unlike the other samples, the first peak of SF_15 was changed to larger size (from 9 to $17 \mathrm{~nm}$ ) between 28 and 91 days (see Figure 5c). This indicates that the volume of mesopores $(4.5-25 \mathrm{~nm})$ of SF_15 were increased due to expansion with curing age. It has been reported that the pores finer than $10 \mathrm{~nm}$ mainly affect shrinkage and creep of hardened cementitious materials [46], and also the degree of capillary tension and stress for drying shrinkage is increased with a finer pore system (below $80 \mathrm{~nm}$ range in pore diameter) $[15,48]$. Thus, this distinct expansion might be attributed to the accelerated drying shrinkage of matrix and resultant micro cracks, as shown in the low W/B (0.25) cement paste with SF (20\% of cement) [49].

\subsection{Compressive Strength}

The compressive strength of prepared kaolinite clay-based mortar increased with SF contents (Figure 8) because of the intended pozzolanic reaction and filling effect. The 91 days compressive strengths of SF_7.5 and SF_15 are 13.37 and $17.34 \mathrm{MPa}$, respectively, which are 2.26 and 2.93 times compared to Ref (5.91 MPa). In particular, SF_15 reached the maximum strength $(27.1 \mathrm{MPa})$ at three days, which is equivalent to normal concrete or cement mortar.

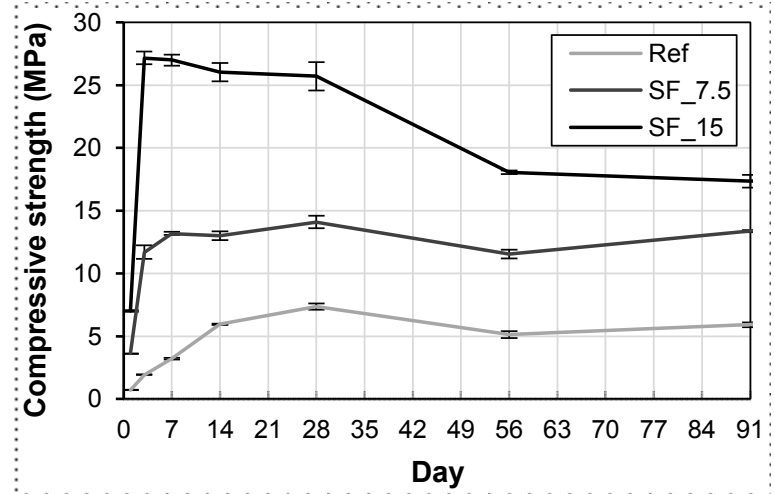

Figure 8. Compressive strength development of kaolinite clay-based mortars. 
However, the compressive strength dropped between 28 and 56 days in all specimens. Ref reached the maximum strength $(7.35 \mathrm{MPa})$ at 28 days, then the strength decreased by $3.05 \%$ at 56 days and increased again by $15.6 \%$ at 91 days. The strength of SF_7.5 decreased by $18.1 \%$ at 56 days and increased by $15.9 \%$ again. On the other hand, a significant strength loss occurred in SF_15 sample without recovery, i.e., the strength steadily decreased after three days until 91 days. In particular, significant strength loss ( $30 \%$ ) occurred between 28 and 56 days.

\subsection{Investigation on Strength Reduction}

Unlike the other samples, the compressive strength of SF_15 steadily decreased after three days (Figure 8). To investigate possible reasons of the strength reduction, pore structures of the samples are additionally discussed in this section. As can be observed in Figure 5, the pore size distributions of Ref and SF_7.5 were almost unchanged between 14 and 91 days, which means that their pore structures stabilized at 14 days. On the other hand, in the case of SF_15, the first peak of pore diameters moved from 9 to $17 \mathrm{~nm}$ between 28 and 91 days (Figure $5 \mathrm{c}$ ). This movement means that the pores around $10 \mathrm{~nm}$ expanded in size (by approximately double), possibly due to the accelerated drying shrinkage with a fine pore structure by excessive SF addition [15,49]. Similarly, Rao has reported that the addition of SF has a significant influence on the drying shrinkage of cement mortar due to the strong pozzolanic reaction and pore size refinement mechanism, especially with $15 \%$ (by wt $\%$ of cement) SF addition. In his study, the shrinkages of cement mortars with $0 \%, 10 \%$, and $15 \%$ of SF showed 75.7, 303, and $812 \mu \mathrm{m} / \mathrm{m}$ at 28 days, and 114, 756, and $1030 \mu \mathrm{m} / \mathrm{m}$ at 60 days [50].

In summary, there is an optimum SF to binder ratio in the developed kaolinite clay-based mortar considering its long-term strength. Greater SF addition above the optimum ratio can have a negative effect on the strength. Thus, based on the conducted experiments herein, it can be concluded that $7.5 \%$ of $\mathrm{SF}$ to binder ratio is more suitable than $15 \%$, considering the long-term performance and economic point of view.

\section{Conclusions}

The results of this study are summarized as follows.

(1) In the heat of hydration test, all samples showed two main peaks regardless of SF addition. $\mathrm{SF}$ addition increased the hydration heat emission. The interesting result is that the cumulative hydration heat of SF_15 was only 5\% higher than that of SF_7.5, although SF content in SF_15 was almost twice than that in SF_7.5. This result reveals that the excessive addition of SF has no chemical effect on the hydration reaction.

(2) The XRD analysis showed that the mortar cured for 28 days contains quartz, kaolinite, illite, remaining calcium hydroxide, calcium carbonate, and clinoptilolite. Unlike Ref, calcium hydroxide was barely detected in two SF samples (SF_7.5 and SF_15), i.e., it was mostly consumed by the intended pozzolanic reaction between hydrated lime and SF. Thus, the intensified hydration reaction that was confirmed by the hydration heat test, was attributed to the intended pozzolanic reaction by adding two mineral admixtures.

(3) The total pore volume of the two samples with SF was lower than that of Ref. Between the two samples with SF, the proportion of the pores, whose size range is similar with that of SF particles, was significantly lower in SF_15 than SF_7.5. This verifies the physical filling effect provided by excessive (unreacted) SF particles. However, in the pore size distribution of SF_15, the first peak was changed from 9 to $17 \mathrm{~nm}$ between 28 and 91 days. This change can be related to the long-term strength reduction in a fine pore structure of SF_15.

(4) The compressive strength of the mortar was increased with SF addition. The main contribution was the intended pozzolanic reaction, but the filling effect also contributed to the strength gain as well. Based on the compressive strength, it was confirmed that the developed kaolinite clay-based mortar with SF has sufficient mechanical properties as a structural material. 
(5) However, there is an optimal SF to binder ratio in the developed mortar. Excessive SF addition resulted in the degradation of long-term compressive strength. Considering price competitiveness and long-term strength, a SF to binder ratio of $7.5 \%$, rather than $15 \%$, is suitable. However, it should be noted that this optimum amount of SF can be different depending on the binder selection (i.e., the ratio of kaolinite clay and calcium hydroxide). The investigated mix design herein can be further expanded to develop other sustainable structural materials, such as natural minerals with low reactivity or waste materials with nonbinding properties.

Acknowledgments: This research was supported by a paper fee from the Institute of Engineering Research, Seoul National University, Republic of Korea and Singapore Ministry of Education Academic Research Fund Tier 1.

Author Contributions: Yang-Hee Kwon and Sung-Hoon Kang conducted experiments, analyzed results, and wrote the manuscript. Sung-Gul Hong and Juhyuk Moon designed the experiments and advised on analysis, data interpretation, and manuscript revision.

Conflicts of Interest: The authors declare no conflict of interest.

\section{References}

1. Torgal, F.P.; Miraldo, S.; Labrincha, J.; De Brito, J. An overview on concrete carbonation in the context of eco-efficient construction: Evaluation, use of SCMs and/or RAC. Constr. Build. Mater. 2012, 36, 141-150. [CrossRef]

2. Yang, K.H.; Hwang, H.Z.; Lee, S. Effects of water-binder ratio and fine aggregate-total aggregate ratio on the properties of Hwangtoh-based alkali-activated concrete. J. Mater. Civ. Eng. 2010, 22, 887-896. [CrossRef]

3. Ahmed, A.M. Physical properties of geopolymer concrete incorporating silica fume and ground granulated blast-furnace slag. Int. J. Sci. Res. 2015, 4, 2415-2419.

4. Yang, K.H.; Hwang, H.Z.; Kim, S.Y.; Song, J.K. Development of a cementless mortar using hwangtoh binder. Build. Environ. 2007, 42, 3717-3725. [CrossRef]

5. Atiş, C.D. Heat evolution of high-volume fly ash concrete. Cem. Concr. Res. 2002, 32, 751-756. [CrossRef]

6. Li, G. Properties of high-volume fly ash concrete incorporating nano-SiO ${ }_{2}$. Cem. Concr. Res. 2004, 34, 1043-1049. [CrossRef]

7. Sobolev, K. Mechano-chemical modification of cement with high volumes of blast furnace slag. Cem. Concr. Compos. 2005, 27, 848-853. [CrossRef]

8. Adam, A.; Molyneaux, T.; Patnaikuni, I.; Law, D. Strength, sorptivity and carbonation of geopolymer concrete. In Challenges, Opportunities and Solutions in Structural Engineering and Construction; CRC Press: Boca Raton, FL, USA, 2010; pp. 563-568.

9. Monteiro, P.J.; Clodic, L.; Battocchio, F.; Kanitpanyacharoen, W.; Chae, S.R.; Ha, J.; Wenk, H.R. Incorporating carbon sequestration materials in civil infrastructure: A micro and mano-structural analysis. Cem. Concr. Compos. 2013, 40, 14-20. [CrossRef]

10. Menéndez, G.; Bonavetti, V.; Irassar, E.F. Strength development of ternary blended cement with limestone filler and blast-furnace slag. Cem. Concr. Compos. 2003, 25, 61-67. [CrossRef]

11. Poppe, A.M.; De Schutter, G. Cement hydration in the presence of high filler contents. Cem. Concr. Res. 2005, 35, 2290-2299. [CrossRef]

12. Pelletier-Chaignat, L.; Winnefeld, F.; Lothenbach, B.; Müller, C.J. Beneficial use of limestone filler with calcium sulphoaluminate cement. Constr. Build. Mater. 2012, 26, 619-627. [CrossRef]

13. Aqel, M.; Panesar, D.K. Hydration kinetics and compressive strength of steam-cured cement pastes and mortars containing limestone filler. Constr. Build. Mater. 2016, 113, 359-368. [CrossRef]

14. Lothenbach, B.; Scrivener, K.; Hooton, R.D. Supplementary cementitious materials. Cem. Concr. Res. 2001, 41, 1244-1256. [CrossRef]

15. Kwon, Y.H.; Kang, S.H.; Hong, S.G.; Moon, J. Acceleration of intended pozzolanic reaction under initial thermal treatment for developing cementless fly ash based mortar. Materials 2017, 10, 225. [CrossRef]

16. Jeong, Y.; Park, H.; Jun, Y.; Jeong, J.H.; Oh, J.E. Influence of slag characteristics on strength development and reaction products in a CaO-activated slag system. Cem. Concr. Compos. 2016, 72, 155-167. [CrossRef]

17. Neto, A.A.M.; Cincotto, M.A.; Repette, W. Drying and autogenous shrinkage of pastes and mortars with activated slag cement. Cem. Concr. Res. 2008, 38, 565-574. [CrossRef] 
18. Zhang, W.; Hama, Y.; Na, S.H. Drying shrinkage and microstructure characteristics of mortar incorporating ground granulated blast furnace slag and shrinkage reducing admixture. Constr. Build. Mater. 2015, 93, 267-277. [CrossRef]

19. Bilim, C.; Karahan, O.; Atiş, C.D.; İlkentapar, S. Influence of admixtures on the properties of alkali-activated slag mortars subjected to different curing conditions. Mater. Des. 2013, 44, 540-547. [CrossRef]

20. Nežerka, V.; Slížková, Z.; Tesárek, P.; Plachý, T.; Frankeová, D.; Petráňová, V. Comprehensive study on mechanical properties of lime-based pastes with additions of metakaolin and brick dust. Cem. Concr. Res. 2014, 64, 17-29. [CrossRef]

21. Papadakis, V.G.; Tsimas, S. Supplementary cementing materials in concrete: Part I: Efficiency and design. Cem. Concr. Res. 2002, 32, 1525-1532. [CrossRef]

22. Siddique, R.; Klaus, J. Influence of metakaolin on the properties of mortar and concrete: A review. Appl. Clay Sci. 2009, 43, 392-400. [CrossRef]

23. Kim, B.J.; Yi, C.; Kang, K.I. Development of alkali-activated binder using hwangtoh without calcination. Constr. Build. Mater. 2014, 58, 206-213. [CrossRef]

24. Malhotra, V.M. Introduction: Sustainable development and concrete technology. Concr. Int. 2002, $24,7$.

25. Go, S.S.; Lee, H.C.; Lee, J.Y.; Kim, J.H.; Chung, C.W. Experimental investigation of mortars using activated Hwangtoh. Constr. Build. Mater. 2009, 23, 1438-1445. [CrossRef]

26. Go, S.S.; Chung, C.W.; Struble, L.J.; Lee, H.C. Pozzolanic activity of Hwangtoh clay. Constr. Build. Mater. 2010, 24, 2638-2645. [CrossRef]

27. Hwang, H.Z.; Kang, N.Y. Preliminary study on traditional earth construction technique use of lime. J. Korea Inst. Ecol. Archit. Environ. 2010, 10, 3-8.

28. Administration, C.H. Cultural Heritage Repair Standard Specification; Design DNA: Daejeon, Korea, 2014; p. 380.

29. Ahn, J.C. A Fundamental Study in the Properties of the Loess Mortar Mixed with Lime (Samwhato). Master's Thesis, Dong-A University, Pusan, Korea, 1997.

30. Hwang, H.Z. A Study on the Method of Activating Kaoline and the Mortar \& Concrete Mixed with Active-Kaoline. Ph.D. Thesis, Seoul National University, Seoul, Korea, 1997.

31. Wang, S.D.; Pu, X.C.; Scrivener, K.L.; Pratt, P.L. Alkali-activated slag cement and concrete: A review of properties and problems. Adv. Cem. Res. 1995, 7, 93-102. [CrossRef]

32. Kim, M.S.; Jun, Y.; Lee, C.; Oh, J.E. Use of $\mathrm{CaO}$ as an activator for producing a price-competitive non-cement structural binder using ground granulated blast furnace slag. Cem. Concr. Res. 2013, 54, 208-214. [CrossRef]

33. Khater, H.M. Effect of silica fume on the characterization of the geopolymer materials. Int. J. Adv. Struct. Eng. 2013, 5, 1-10. [CrossRef]

34. Malhotra, V.M.; Mehta, P.K. Pozzolanic and Cementitious Materials; Gordon and Breach Publishers: Amsterdam, The Netherlands, 1996; Volume 1.

35. Diamond, S.; Sahu, S. Densified silica fume: Particle sizes and dispersion in concrete. Mater. Struct. 2006, 39, 849-859. [CrossRef]

36. Cement-Test Methods-Determination of Strength; ISO 679:2009; International Organization for Standardization: Geneva, Switzerland, 2009; p. 29.

37. Standard Practice for Mechanical Mixing of Hydraulic Cement Pastes and Mortars of Plastic Consistency; ASTM C305; Annual Book of ASTM; American Society for Testing and Materials (ASTM): West Conshohocken, PA, USA, 2014; p. 3.

38. Belsky, A.; Hellenbrandt, M.; Karen, V.L.; Luksch, P. New developments in the Inorganic Crystal Structure Database (ICSD): Accessibility in support of materials research and design. Acta Crystallogr. Sect. B 2002, 58, 364-369. [CrossRef]

39. Standard Test Method for Compressive Strength of Hydraulic Cement Mortars (Using 2-in or [50-Mm] Cube Specimens); ASTM C109/C109M; Annual Book of ASTM; American Society for Testing and Materials (ASTM): West Conshohocken, PA, USA, 2013; p. 10.

40. Gameiro, A.; Silva, A.S.; Faria, P.; Grilo, J.; Branco, T.; Veiga, R.; Velosa, A. Physical and chemical assessment of lime-metakaolin mortars: Influence of binder: Aggregate ratio. Cem. Concr. Compos. 2014, 45, $264-271$. [CrossRef] 
41. Fernández, J.M.; Duran, A.; Navarro-Blasco, I.; Lanas, J.; Sirera, R.; Alvarez, J.I. Influence of nanosilica and a polycarboxylate ether superplasticizer on the performance of lime mortars. Cem. Concr. Res. 2013, 43, $12-24$. [CrossRef]

42. Bhattacharyya, K.G.; Gupta, S.S. Adsorption of a few heavy metals on natural and modified kaolinite and montmorillonite: A review. Adv. Colloid Interface Sci. 2008, 140, 114-131. [CrossRef] [PubMed]

43. Khan, M.I.; Lynsdale, C.J. Strength, permeability, and carbonation of high-performance concrete. Cem. Concr. Res. 2002, 32, 121-131. [CrossRef]

44. Skjolsvold, O. Carbonation depths of concrete with and without condensed silica fume. Spec. Publ. 1986, 91, 1031-1048.

45. Collins, F.; Sanjayan, J.G. Effect of pore size distribution on drying shrinking of alkali-activated slag concrete. Cem. Concr. Res. 2002, 30, 1401-1406. [CrossRef]

46. Wu, Z.; Shi, C.; Khayat, K.H. Influence of silica fume content on microstructure development and bond to steel fiber in ultra-high strength cement-based materials (UHSC). Cem. Concr. Compos. 2016, 71, 97-109. [CrossRef]

47. Mehta, P.; Monteiro, P.J. Concrete, Microstructure, Properties and Materials; McGraw-Hill Publishing: London, UK, 2006.

48. Lura, P.; Jensen, O.M.; van Breugel, K. Autogenous shrinkage in high-performance cement paste: An evaluation of basic mechanisms. Cem. Concr. Res. 2003, 33, 223-232. [CrossRef]

49. Lura, P.; Durand, F.; Loukili, A.; Kovler, K.; Jensen, O.M. Compressive strength of cement pastes and mortars with superabsorbent polymers. In Proceedings of the International RILEM Conference on Volume Changes of Hardening Concrete: Testing and Mitigation, Lyngby, Denmark, 20-23 August 2006.

50. Rao, G.A. Long-term drying shrinkage of mortar-Influence of silica fume and size of fine aggregate. Cem. Concr. Res. 2001, 31, 171-175. [CrossRef]

(C) 2017 by the authors. Licensee MDPI, Basel, Switzerland. This article is an open access article distributed under the terms and conditions of the Creative Commons Attribution (CC BY) license (http:/ / creativecommons.org/licenses/by/4.0/). 